\title{
Rodas de conversa e pesquisa: reflexões de uma abordagem etnográfica $^{12}$
}

\section{Talking circles and research: reflections of an ethnographic approach}

(i) Universidade Federal do Rio Grande do Sul - UFRGS, Porto Alegre, RS, Brasil.

https://orcid.org/0000-0001-5041-4939, leandropinheiro75@gmail.com.

\begin{abstract}
Resumo:
O artigo discute a produção de rodas de conversa como técnica em pesquisa qualitativa na área de educação, problematizando-a desde incursões de inspiração etnográfica em contextos de periferia urbana. Para efeito da argumentação proposta, toma-se a interlocução construída com moradoras idosas de um bairro de Porto Alegre/RS, entre os anos de 2014 e 2016, mediante a realização de encontros em seus locais de residência. Consideraram-se as contribuições de Georg Simmel e Michel de Certeau para reflexões sobre a produção da "conversa sociável” e acerca das "artes de dizer" populares, respectivamente, propondo uma interpretação da dinâmica da conversação e da forma da narração. Neste sentido, no percurso metodológico narrado, destaca-se a defluência cultural da "conversa" e, para o caso em análise, aventa-se a associação da dinâmica das rodas coproduzidas à atuação daquelas mulheres no âmbito comunitário e consonante a uma estética relacional em prol dos laços de reciprocidade em seu cotidiano.

Palavras-chave: rodas de conversa, narrativas, sociabilidades, cotidiano.
\end{abstract}

${ }^{1}$ O presente trabalho foi realizado com apoio da Coordenação de Aperfeiçoamento de Pessoal de Nível Superior (Capes)- Código de Financiamento 001.

${ }^{2}$ Normalização, preparação e revisão textual: Douglas Mattos (Tikinet) - revisao@tikinet.com.br 


\begin{abstract}
:
This paper discusses the use of talking circles as technique in qualitative research in education by problematizing it vis-à-vis the incursions of ethnographic inspiration in urban peripheries. Regarding the proposed argumentation, interlocution is held with dwellers of Porto Alegre/RSBrazil, by means of meetings at their homes between the 2014 and 2016. The contributions of Georg Simmel and Michel de Certeau were taken into consideration for reflections on the production of the "sociable talk." and on the popular "arts of saying", respectively, proposing an interpretation of the dynamics of the conversation and of the form of narration. Therefore, regarding the deployed methodological course, the cultural flow of the "talk" stands out and, for the case under analysis, the dynamics of the coproduced talking circles are associated to the performance of those women within the neighborhood and, also, to a relational aesthetics in favor of reciprocity ties in their daily lives.
\end{abstract}

Keywords: talking circles, narratives, sociability, everyday life.

Entre os recorrentes esforços de qualificação da pesquisa na área de educação, as buscas por diversificação de técnicas qualitativas, ou pelo aprimoramento destas, são usuais e conhecidas nas práticas e interlocuções do campo. Neste sentido, as iniciativas orientadas a processos dialógicos nas investigações, com vistas às reflexões mútuas que possam gerar e em articulação com aspirações a uma maior plausibilidade das interpretações elaboradas, parecemnos significativamente atinentes.

A proposição de rodas de conversa tem sido um dos modos de consubstanciar dialogicamente intentos educativos e sistematização de informações desde uma dinâmica que, potencialmente, estabelece condições para a produção de saberes e reflexividades em partilha. E percebemos diferentes apropriações metodológicas neste caso, sob distintos propósitos e com maior ou menor diretividade, o que, inclusive, intentaremos problematizar neste trabalho.

Após acumularmos algumas vivências na produção de narrativas em contextos de periferia urbana, especialmente com a realização de entrevistas semiestruturadas sobre itinerários biográficos, também incorporamos as rodas de conversa como artifício para interlocução em campo. Nosso objetivo, partindo da experiência que narraremos neste artigo, é trazer reflexões sobre a produção de tal técnica desde um olhar etnográfico, considerando a 


\section{pro.posıções}

$e$-ISSN 1980-6248

http://dx.doi.org/10.1590/1980-6248-2019-0041

virtualidade das rodas no compartilhamento de experiências, porém discutindo especialmente o que interpretamos a partir da dinâmica da conversação e a forma das narrações.

Partiremos de incursões feitas a uma das localidades de periferia da cidade de Porto Alegre/RS, quando coproduzimos rodas de conversa com moradoras idosas daquele contexto. A pesquisa previa diferentes técnicas para a produção de narrativas acerca do cotidiano e das redes de pertença, sendo as rodas tomadas em complementaridade. A análise do percurso na construção destas contará com as contribuições de Simmel (2006) e Certeau (2011), no que tange à "conversa sociável” e às "artes de dizer", respectivamente.

No texto que segue, apresentaremos uma sucinta análise dos usos das rodas de conversa, para chegarmos, depois, aos referentes de nossas proposições metodológicas. Então, narraremos o percurso construído em campo, tendo em conta a interpretação do experienciado conforme nos inspiram os autores mencionados.

\section{Sobre rodas de conversa e sua apropriação}

Em que pese verificarmos um uso crescente das rodas de conversa entre práticas educativas e de pesquisa, as formas assumidas quando de sua operacionalização podem variar consideravelmente. Em geral, falamos da composição de círculos para conversação mediante uma provocação temática. Há também uma ênfase na participação ou mesmo no protagonismo dos integrantes das rodas, visando partilha de saberes e reflexividade sobre experiências individuais ou coletivas. A partir daí, a leitura de diferentes iniciativas na apropriação da técnica indica, simultaneamente, particularidades a depreender e intersecções com outros modos de interlocução coletiva (Bedin \& Pino, 2018; Melo \& Cruz, 2014; Moura \& Lima, 2014; Sampaio, Santos, Agostini, \& Salvador, 2014; Warschauer, 2004).

Característica que poderíamos destacar logo de início é a condição culturalmente defluente das rodas de conversa. As pessoas convidadas a integrá-las carregam consigo vivências neste sentido; a chegada ao encontro não é isenta de experiências próprias em práticas de conversação e partilha, que podem estar ligadas a ações educativas reconhecidas no campo, articuladas a costumes comunitários ou, de maneira mais abrangente, associadas às relações sociáveis que produzimos. E podemos encontrar referências que o sinalizam pelo menos em 
parte, seja aludindo aos círculos de cultura (de perspectiva freireana), seja evocando iniciativas coletivas na difusão de saberes da tradição (Warschauer, 2004).

Simmel (2006), quando desenvolve seu exercício analítico da sociabilidade (como "exemplo de sociologia pura"), faz referência à "conversa" e nos lembra de que, se na seriedade da vida ela se presta a diferentes assuntos, em sua versão sociável se converte numa "arte". A interação teria, assim, um fim em si mesmo, e o sentido se encontraria no jogo funcional da conversação. A situação ideal, neste sentido, seria aquela em que os atores em interlocução não dão demasiada proeminência às suas singularidades, tampouco sobrevalorizam o conteúdo do colóquio, em favor da sociação em curso. Daí resulta, segundo o autor, que o assunto de uma conversa sociável possa mudar com facilidade.

Entretanto, e passando a um segundo aspecto, a produção de rodas de conversa tal como identificada na literatura tende a diferir de uma "conversa sociável". De maneira geral, trata-se de iniciativas que associam pesquisa e educação e, logo, interpõem uma intencionalidade educativa. Com ela, advém certa diretividade na organização das rodas, o que pode variar significativamente quanto à intensidade e aos modos de condução: encontramos casos baseados apenas na delimitação de eixos iniciais para debate, bem como a organização detalhada de dinâmicas de grupo e disposição de frases para interpretação e interlocução.

Não raro, contudo, a utilização de rodas de conversa é estabelecida sob o propósito de dar voz aos sujeitos, visando possibilitar sua participação efetiva no processo, à medida que lhes são facultadas falas dialógicas pelas quais se espera o aporte de seus saberes. Os exemplos a que tivemos acesso até o momento professam uma busca por procedimentos democratizantes, que oportunizem partilhas de experiências de diferentes matrizes culturais e/ou, ademais, criem condições para reflexões críticas sobre determinada prática ou condição. Aqui, as referências à obra de Paulo Freire são patentes.

As rodas de conversa são reputadas também por sua potencialidade na produção de narrativas individuais e/ou coletivas. Então, os depoimentos apresentados nas discussões são tomados para sistematização não só com finalidade devolutiva, mas com o fito de elencar conteúdos e sustentar análises sobre inserções sociais, vivências de práticas específicas, experiências subjetivas em dado tema. Desde tal aspecto, características de outros artifícios metodológicos são associados na delimitação de formas de organizar e desenvolver as rodas, como são exemplos os "grupos focais" ou os "grupos de discussão", não obstante as possíveis 


\section{pro.posıções}

$e$-ISSN 1980-6248

http://dx.doi.org/10.1590/1980-6248-2019-0041

incompatibilidades existentes entre os usos convencionais de cada um desses modos de interlocução.

Uma breve retomada de algumas experiências no campo da educação pode, a um só tempo, explicitar as associações de procedimentos e trazer exemplos da apropriação de rodas de conversa. Melo e Cruz (2014) apresentam a experiência com estudantes e professores de uma escola pública de Ensino Médio acerca da influência da adolescência na relação entre os sujeitos da sala de aula. Ao longo do artigo, os autores mencionam que, além da coleta de informações, as rodas poderiam promover diálogos, "ampliando percepções sobre si e o outro" (p. 32), aludindo a peculiaridades reflexivas. Para organizar a dinâmica de conversação, buscaram aproximação à técnica de grupo focal sob o argumento de que a interatividade prevista em ambos os procedimentos permitiria a assunção das características de um ao outro. Assim, referências sobre grupos focais são tomadas para delimitar o modo de ação em campo: foco no assunto em pauta, ambiência aberta às discussões, construção de relação de confiança com o moderador, entre outras. Os pesquisadores efetivaram duas rodas (uma com professores e outra com alunos), gravadas em áudio e vídeo. Mencionam, a esse respeito, a dificuldade de manter o foco no assunto de pauta e a necessidade de repetir o encontro com o grupo de professores. $\mathrm{O}$ pesquisador não cogita a problematização da conversação destoante, da mesma forma que não estabelece diferenciações claras com o grupo focal. Em que pese a aproximação a outra técnica, pode-se depreender de sua argumentação que a referência às rodas de conversa é singularizada por uma potencialidade dialógica e formadora.

Noutro exemplo, Bedin e Pino (2018) narram pesquisa voltada ao debate sobre o "ser professor na contemporaneidade", efetuada em rodas de conversa com professores de química em formação universitária inicial. Os encontros foram antecedidos de levantamentos por questionário, e as transcrições posteriores tratadas mediante análise textual discursiva. Além da finalidade investigativa, afirmavam que as rodas de conversa seriam uma "estratégia política libertadora e que favorecem a emancipação" (p. 228). Os pesquisadores procederam mediante a disposição de questões que os participantes deveriam escolher e responder individualmente em escrita de poucas palavras, deixando a resposta junto da pergunta para que outro, depois, a tomasse e lesse ao grupo. Então, o leitor deveria tentar explicar a resposta do autor, e este poderia complementá-lo em seguida. Como se pode perceber, a condução das rodas se deu de forma bastante estruturada neste caso. 


\section{pro.posições}

$e$-ISSN 1980-6248

http://dx.doi.org/10.1590/1980-6248-2019-0041

Já Moura \& Lima (2014) procuram destacar o uso de rodas de conversa para a produção de narrativas mnemônicas entre pares, configurando um espaço de trocas em que o pesquisador integra a conversa e a produção de dados. Dessa forma, mencionam a criação de um ambiente propício à escuta, ao diálogo e à singularidade das partilhas. Com apoio em Warschauer (2004), apostam na reconstrução reflexiva de conceitos e de argumentos pelos participantes à medida que estes se dispõem à interlocução efetiva com o outro. No que tange à sua pesquisa, as autoras narram a realização de três rodas com dez participantes (incluindo elas próprias), associadas a três eixos temáticos pré-definidos: "como deve ser o professor de Ensino Superior"; “como o professor soluciona as demandas de sala de aula, entre improvisos e ineditismos"; e "como a prática ajuda a atuar na docência". A dinâmica partia dos eixos em conversas livres. Então, a análise se dedicou à categorização do que fora transcrito, atuando basicamente sobre o que fora verbalizado.

\section{O contraste com outras técnicas: um exercício analítico}

Nesse sucinto extrato, podemos perceber já certa variedade nas formas de condução e nos ânimos de diretividade em rodas de conversa. Retornemos, então, aos artifícios metodológicos associados. Com vistas à distinção de técnicas, propósitos e configurações interativas convencionais, tomemos os grupos focais e os grupos de discussão. Embora possam ter em comum a produção de discussões coletivas, a disposição de depoimentos sobre temáticas determinadas e a atenção à palavra dos participantes durante os encontros, podemos perceber usos e objetivos convencionalmente distintos.

Segundo Weller (2006), o grupo focal começou a ser utilizado no pós-guerra anglo-saxão em pesquisas de marketing, tem sido utilizado atualmente na sondagem de opiniões sobre temas determinados e os integrantes, muitas vezes, não se conhecem. Pode ser importante, aliás, que se considere sujeitos de posições a princípio contrastantes ou estratificadas na formação grupal. Trata-se, ainda, de procedimento adotado para compreensão de modos de recepção de informações e processos psicossociais de formação de opiniões ou, em usos clínicos, de sentimentos e crenças. A interlocução se dá pela ação de um facilitador cujas intervenções, mesmo que discretas, mantêm-se atentas a delimitar a discussão aos assuntos e propósitos previstos pelo investigador. A interpretação das informações tende, então, a uma análise das influências mútuas entre participantes no curso de um debate temático (Gondim, 2003). 


\section{pro.posıções}

$e$-ISSN 1980-6248

http://dx.doi.org/10.1590/1980-6248-2019-0041

Já o grupo de discussão, embora tenha, em sua versão espanhola crítica, uma origem contextual comum (Meinerz, 2011), destina-se mais comumente ao conhecimento de experiências sociais dos sujeitos e sua relação com os contextos em que se inserem. Normalmente, é produzido com pessoas de vivências ou pertenças em comum, e que se conhecem, inclusive. Procura-se produzir um espaço público de participação que evoque discursos e modos de interação de determinado segmento social - de classe, gênero, idade. $\mathrm{O}$ pesquisador procuraria intervir o mínimo possível, apenas estimulando narrativas de vivências - e não somente descrição de fatos e opiniões (Weller, 2006). Embora se distinga do grupo focal nos objetivos e forma de condução, essa abordagem também prevê a repetição da técnica com diferentes agrupamentos com fitos comparativos, pelo que se aconselha não alterar o tópicoguia e o modo de condução.

Mesmo que possamos reconhecer consequências reflexivas, não há aí necessariamente intencionalidade educativa ou foco explícito na partilha de saberes e interpretações críticas como nas rodas de conversa que a literatura exemplifica. De outra parte, em versões abertas, estas podem ser ainda menos estruturadas que os grupos focais e de discussão. Neste sentido, no que tange aos resultados educativos, caso se optasse pela realização de conversações com propósitos idênticos entre coletivos diferentes, seria de se esperar que as resultantes fossem diversas, cabendo mais o contraste de experiências dialógicas distintas do que a comparação de casos.

Entretanto, no que concerne à sistematização das informações partilhadas, se, por um lado, entendemos que a repetição pode ser mais profícua na interlocução com um mesmo grupo, aprofundando conhecimento de sua realidade social, a realização de rodas de conversa com agrupamentos distintos, por outro, demandaria cuidados adicionais. Seria preciso atentar também ao princípio de contraste das produções coletivas e, somente sob condições determinadas, estabelecer vetores de comparação. Por outras palavras, entendemos que a comparação deveria ser antecedida da interpretação congruente de informações verbalizadas e modos de participação, destacadamente dinâmicas de conversação e formas de narração ${ }^{3}$. Se tal artifício não desfaz a singularidade de cada evento, ele ao menos contribui para a produção de

\footnotetext{
${ }^{3}$ Estamos cientes de que, por prudência metodológica, essa recomendação poderia ser adotada por outras técnicas na coleta de dados, particularmente aquelas dirigidas ao conhecimento de relações, práticas e discursos socialmente contextualizados. Não seria, portanto, traço distintivo das rodas de conversa. Contudo, assumindo aqui a peculiaridade dialógica e a intencionalidade educativa recorrentemente proferida pela literatura consultada, cremos que a singularidade dos coletivos teria lugar de mais expressão, considerando que tomar as vivências em contraste e intentar uma mirada aos modos de conversação e narração se colocam com necessidade realçada, em atenção ao rigor heurístico das inferências. $\mathrm{O}$ caso problematizado neste artigo procura caminhar neste sentido.
} 
mais elementos a considerar na caracterização de experiências coletivas postas lado a lado na análise.

Feitas tais considerações, por ora, gostaríamos de realçar a variedade de composições estabelecidas sob a denominação "roda de conversa", como forma de remetermos nossas reflexões aos propósitos a elas associados normalmente. Ainda que mantenhamos objetivos educativos ou reflexivos e perspectivas dialógicas, os modos de condução diversificam-se significativamente quando observamos os relatos das experiências. É forçoso frisar, neste sentido, o risco de reforço das assimetrias culturais e simbólicas presentes entre os participantes das rodas quando estas são demasiadamente dirigidas, obliterando, ao menos parcialmente, a horizontalidade pretendida na partilha. Ou, de outra maneira, o esmaecimento da dialogicidade, e da compreensão da alteridade que ela encerra, ao se realçar a teleologia em uma prática, invisibilizando as formas de atuação dos sujeitos em diálogo.

Não é nosso propósito, aqui, traçar apreciações sobre estatuto das vivências em rodas de conversa. Apenas compartilhamos as contradições de um fazer que, desde a experiência que pretendemos abordar neste artigo, entendemos constituintes também do que produzimos em campo. Da mesma forma, resumimos aspectos que parecem perpassar a proposição das "conversas" e percebemos igualmente presentes no que procuraremos narrar. Sem perdê-los de vista, então, a proposição de leitura de inspiração etnográfica das rodas de conversa que construímos orienta-se a partilhar determinado modo de fazer e elementos outros a considerar.

\section{As rodas e a inspiração etnográfica}

O método etnográfico pressupõe a permanência no território e a integração ao fluxo dos acontecimentos. Aí se situam leituras de hábitos, códigos e redes a que se integram os sujeitos de pesquisa, em descrições densas do que se percebe e, também, dos efeitos da presença e dos modos de interagir (Rocha \& Eckert, 2008). Estar em campo corresponde, neste sentido, à disposição em interpretar tomadas de posição e narrações e, ademais, a se reconhecer interpretado por aqueles com quem dialogamos. A essa condição se associa certa reflexividade demandada dos interlocutores por esses "estranhos" que se fazem presentes em determinado momento, carregando perguntas e proposições. 


\section{pro.posıções}

$e$-ISSN 1980-6248

http://dx.doi.org/10.1590/1980-6248-2019-0041

O resultado desse esforço de imersão e diálogo, de registro do experienciado em campo, é, além de um conjunto de interpretações disciplinarmente circunscrito, um exercício narrativo desde o qual o autor agencia fatos, sujeitos e tempos na busca de inteligibilidade referenciada. Trata-se da configuração da temporalidade do pesquisador entre suas vivências em campo e a elaboração de seu diário (Rocha \& Eckert, 1998). E parte desse esforço criativo desejamos apresentar aqui, como uma análise das conversações que construímos, problematizando a interação produzida nas rodas e a maneira como foram incorporadas ao fluxo do cotidiano daquelas pessoas.

Assim, numa modalidade etnográfica, consideramos oportuno, pelo menos por um momento, tomar a roda de conversa à parte do vetor teleológico educacional e da análise das informações nos depoimentos, para, de outro modo, narrar os "conteúdos" da dinâmica das conversações e da forma das narrações na roda. Para tanto, cabe considerar as conversas sem induções temáticas demasiadas, ou como algo não tão disciplinado ou orientado nos procedimentos. Entendemos que, em modalidade aberta, podemos vislumbrar transversalidades, disputas e sobreposições: transversalidades porque as evocações e sintonias são múltiplas desde as narrativas em coletivo; disputas e sobreposições porque a conversa se torna um jogo de protagonismos e há um movimento limítrofe entre a acolhida à singularidade do outro e a permanência/estabilidade do grupo (como sugere Simmel, 2006).

A experiência com rodas de conversa que trazemos à discussão foi levada a cabo mediante incursões com moradoras idosas do bairro Restinga, na cidade de Porto Alegre, entre 2014 e 2016. Pesquisávamos redes de pertença em cotidianos de localidades periféricas da cidade e, dialogando com diferentes grupos etários, chegamos à interlocução com integrantes da ala das baianas de uma escola de samba. Entre idas e vindas, em dinâmica relativamente aberta ao ingresso de novas participantes, consolidamos um núcleo estável de seis pessoas, com idades entre 60 e 75 anos.

Tínhamos conosco a proposta de conversações ancoradas no uso de fotografias. Inicialmente, convidamos nossas interlocutoras a trazerem seus registros e narrarem personagens, relações e fatos que neles se indiciassem. Depois, em prática que ocupou a maior parte de nosso trabalho, convidamo-las a realizarem ensaios fotográficos no bairro, em temas do cotidiano. Fazíamos encontros quinzenais nas residências das participantes das rodas, nos quais as fotos eram expostas sobre a mesa e, então, estabelecíamos interlocuções abertas sobre 


\section{pro.posıções}

$e$-ISSN 1980-6248

http://dx.doi.org/10.1590/1980-6248-2019-0041

as motivações na produção das imagens e os sentidos atribuídos àqueles artefatos. No período final de nossas incursões, quando já nos tomavam em familiaridade às suas rotinas, filmamos alguns dos encontros.

Por intermédio das conversas, diversas narrativas se consubstanciavam. Se começávamos com relatos sobre as imagens, não tardavam a perpassar os diálogos experiências associadas à história do bairro e aos itinerários daquelas senhoras. Elas se mostravam motivadas pela possibilidade de partilhar lembranças, as quais, dada a longevidade de suas trajetórias, consolidavam vivências estendidas de quadros culturais e familiares. Como afirmaria Bosi (1994), memórias elaboradas em condição existencial já menos incitada pelas projeções de futuro, com um "pano de fundo" definido e prestes a ser compartilhado.

Como procuraremos detalhar mais adiante, os encontros foram gradualmente modulados pelas participações de nossas interlocutoras. A duração das reuniões foi estendida pela integração de momentos à mesa, quando compartilhamos comida e conversações não dirigidas, e familiares das participantes se juntavam a nós, inclusive. Não programamos tal dinâmica, apenas a respeitamos e acompanhamos no percurso.

No atendimento ao propósito de pesquisa mencionado na introdução, as conversações foram consideradas quanto à configuração que assumiam, aventando, aqui, articulações com as “artes de fazer" cotidianas (Certeau, 2011) e os modos sociáveis (Simmel, 2006) do contexto de nossas incursões ${ }^{4}$. Cabe assinalar, neste caso, que as rodas de conversas que então produzimos se articulavam à utilização de outras técnicas em nossa imersão, como as entrevistas narrativas (Jovchelovitch \& Bauer, 2002) e a observação (ademais da já referida produção de imagens fotográficas).

\footnotetext{
${ }^{4}$ Convém aludir, aqui, às importantes contribuições de Gabriel Tarde no que tange às problematizações sobre a conversa. Com ele, poderíamos nos acercar de certa categorização e, provavelmente, situarmos nossas interlocuções entre as conversas das pequenas comunidades (ou das cidades pequenas) e as conversações facultativas e de trocas. Talvez fosse possível, ainda, relacionar suas elaborações às caracterizações de Simmel (2006) da conversa sociável. Contudo, Tarde (2005) está preocupado com a produção da opinião e os modos de sua imitação/propagação, e não discute tão detidamente sua articulação com a sociabilidade, elemento importante no contexto da pesquisa aqui apresentada, com vistas à compreensão situada das tomadas de posição narrativas e sociáveis de nossas interlocutoras. Além disso, mesmo reconhecendo os efeitos de aparatos massivos na conformação de assuntos (ontem a imprensa, hoje diversos dispositivos de mídia social), não nos orientamos epistemologicamente à propensão diferenciadora inata e infinitesimal que esse autor possibilita - se acompanharmos leituras como a de Marras (2007), por exemplo -, que, cremos, demandaria outras ferramentas metodológicas. Nos modestos limites deste texto, dedicamo-nos a considerar os movimentos conservacionais e narrativos e sua homologia com forças éticas contextualizadas e artes de fazer.
} 


\section{pro.posıções}

$e$-ISSN 1980-6248

http://dx.doi.org/10.1590/1980-6248-2019-0041

Nesse sentido, para efeito da análise das informações que produzimos no processo, organizamos dois quadros-síntese correlacionados, reunindo registros de diferentes fontes. Em diário de campo, detemo-nos a apontamentos abrangentes, incluindo a descrição densa: de especificidades dos locais, das dinâmicas de interação, de elementos das estruturas de contação (personagens, ações, contextos, enredo) e de modos de atuar em narração.

Pelas transcrições de entrevistas individuais, buscamos práticas sociais, redes relacionais e contextos de atuação predominantes. As conversações filmadas, e igualmente transcritas, se prestavam a dois vetores interpretativos. De um lado, atentávamos para os mesmos itens descritos na análise dos itinerários biográficos; de outro, considerávamos as falas associadas às performances narracionais e as dinâmicas de interação percebidas em vídeo.

De uma parte, assim, compomos um quadro relativo às pertenças, reunindo redes relacionais, práticas sociais e contextos de atuação versados em itinerários biográficos, causos contados e narrativas sobre as fotografias. De outra, esboçamos um painel das dinâmicas de interação e de performances narracionais (individuais e/ou coletivas). As primeiras compreendidas desde as coparticipações e protagonismos e as intermediações dialógicas e temáticas; as segundas, observadas nos elementos estruturais dispostos e, sobretudo, nos modos de atuação na narração.

De posse de tais sínteses, assumimos as hipóteses heurísticas trabalhadas neste artigo, a saber: da homologia entre "artes de fazer" e "artes de dizer"; e da aproximação entre rodas de conversa, modos sociáveis de interação e forças éticas da sociedade, com apoio de Certeau (2011) e Simmel (2006), respectivamente. Para tanto, foi preciso, ainda, ter em mente as diferenças dos conteúdos veiculados segundo os artefatos usados para evocação narrativa. Neste particular, as fotografias precisam ser reconhecidas na disposição cultural à produção do supostamente belo e/ou digno de registro (Martins, 2009), em contraste com o construído nas entrevistas ou conversações espontâneas, conforme procuraremos considerar adiante em nossas reflexões, após a apresentação das incursões em campo. 


\section{pro.posıções}

\section{Contexto e interlocutoras}

Quando se chega à Restinga, é possível perceber a semelhança com cidades da região metropolitana de Porto Alegre. Localidade atravessada por uma avenida repleta de estabelecimentos comerciais e com intenso tráfego de veículos, que liga regiões distintas do município e faz daquele espaço também um lugar de trânsito (e não só de moradia). Ali, reside um contingente populacional superior ao de muitas cidades do interior do Estado. Segundo dados do Censo 2010, seriam cerca de 60 mil habitantes (ObservaPOA, 2018), mas ativistas afirmam que chegaria a mais 150 mil hoje.

Apesar dos esforços dos moradores, os serviços públicos oferecidos ainda são insuficientes e as condições de vida comparativamente vulnerabilizadas. Tomando-se análises comparativas do Observatório de Porto Alegre, com base em informações dos censos produzidos pelo Instituto Brasileiro de Geografia e Estatística, observa-se a confluência de diferentes marcadores sociais de desigualdade, destacando-se condições precarizadas de renda e escolarização (ObservaPOA, 2018). Ademais, é corrente a estigmatização dos oriundos do bairro, de maneira que a população costumava ser associada genericamente a situações de violência e criminalidade.

Nossas interlocutoras residiam na Restinga Velha, parte mais antiga da localidade. Quando não estavam ocupadas em suas rotinas domésticas, todas elas se mostravam em busca por sociabilidade e atividades para fruição coletiva (coral, escola de samba, viagens, atuação política etc.). Em boa medida, as atividades de lazer vinham sendo oportunizadas após a aposentadoria, dado que possuíam mais tempo livre e, com os filhos relativamente independentes, podiam dedicar também recursos pecuniários a atividades e passeios com grupos de pessoas de sua faixa etária.

Contudo, essa situação diferia a cada caso, conforme se organizavam os arranjos familiares. Estas idosas eram referência para as tomadas de decisão, quando não eram participantes ativas no sustento familiar, aproximando-se da realidade nacional de aumento do número de famílias chefiadas por idosos, provocado, de um lado, pela consolidação de benefícios sociais até então e, de outro, pela condição instável e precária de acesso dos jovens ao mercado de trabalho (Buaes, 2015). 


\section{pro.posıções}

$e$-ISSN 1980-6248

http://dx.doi.org/10.1590/1980-6248-2019-0041

Nesse cenário, é preciso ter em mente também que a composição dos lares de nossas interlocutoras, a exemplo das dinâmicas familiares de grupos populares (Fonseca, 2004), organizava-se em composições diversas. Incluía-se a existência de mais de uma casa em cada pátio, e os residentes destas viviam de maneira interdependente e, de modo geral, mediante a recorrente configuração de laços de reciprocidade.

As arenas de atuação narradas carregavam condicionamentos de gênero e etnia (associados a materiais), e os trabalhos logrados eram aqueles de remuneração inferior. Ratts (2003) traz, neste sentido, análise pertinente das relações entre gênero, raça e espaço nas trajetórias de mulheres negras. Acaba por reportar um histórico de migrações e inserções laborais precarizadas, delimitando territórios de circulação e tipos de trabalho na cidade e referindo a recorrência dos serviços como empregada doméstica.

Traçada, pois, uma sucinta caracterização do contexto de nosso trabalho e das moradoras que compartilharam as rodas conosco, podemos passar ao percurso de nossa imersão.

\section{O percurso em rodas}

Saindo da avenida central do bairro, embora percebêssemos um ou outro estabelecimento comercial, assim como uma ou outra igreja, predominavam as residências. Nas proximidades das moradas de nossas interlocutoras, naquela variedade de formatos, nossos olhares de passagem sentiam certa estrutura comum; talvez o pequeno tamanho dos terrenos e a contiguidade das casas, o jeito como estavam dispostos os muros na frontaria (em geral, feitos de tijolos, sem pintura ou tingidos com cal, em altura suficiente para inibir entradas fortuitas), os pátios em que se avistavam algumas plantas e onde, adentrando, víamos pequenas hortas eventualmente, ou as paredes por rebocar ou pintadas em cores opacas. Elementos que pareciam nos contar que as residências eram edificadas nas intermitências da possibilidade.

Aproximamo-nos de nossas companheiras de percurso por intermédio de contato da escola de samba do bairro, que nos levou a integrantes da ala das baianas. Nosso primeiro encontro foi na casa de Loiva ${ }^{5}$, que se dispôs a convidar suas colegas e ofereceu sua residência

\footnotetext{
${ }^{5}$ Os nomes que ocasionalmente citaremos são fictícios.
} 


\section{pro.posıções}

$e$-ISSN 1980-6248

http://dx.doi.org/10.1590/1980-6248-2019-0041

para a ocasião. Seria também por lá que realizaríamos a maior parte de nossas rodas de conversa, uma moradia pequena de alvenaria, em pátio onde estava também a casa de sua filha e sua neta. Entre o muro da frente e a edificação, uma pequena área com flores, árvores frutíferas e algumas hortaliças; à esquerda, havia ainda a casa de sua cachorra.

Loiva sempre nos encontrava ao portão, demonstrando gentil receptividade. $\mathrm{Na}$ primeira vez que nos achegamos por lá, também foi assim, com a acolhida nuançada, porém, pela interposição de certa cerimônia do contato entre desconhecidos. Recebeu-nos e logo nos conduziu até a sala da casa. Ali, ao lado direito da porta, encontramos um pequeno sofá vermelho coberto por uma manta; ainda à direita, próxima à parede e abaixo da escada de madeira que levava ao segundo piso, a mesa para as refeições e conversas, que viríamos a usar com frequência. Ao fundo, uma pequena estante com um aparelho de TV grande e vistoso e algumas fotografias e adereços confeccionados pela dona da casa ou sua filha artesã, dispostos em diferentes pontos do móvel. Ali também mais alguns objetos acumulados em um canto ou outro, como se deixados no curso do cotidiano, aguardando destino mais apropriado. Por fim, à esquerda, a porta de acesso à cozinha e outro sofá. Nas paredes, várias fotos de familiares e registros das formaturas dos filhos, motivo de orgulho da dona da casa.

Então, procedemos uma rodada de apresentações pessoais e falamos de nossa proposta de interlocução. Para as primeiras rodas de conversa, pedimos que trouxessem algumas das fotografias que possuíam e sobre as quais gostariam de falar. Foi um modo de aproximação, pelo qual soubemos ainda das redes de pertença e inserções históricas na localidade. Mostraram registros de festividades de família e de eventos na escola de samba sobretudo, ambientadas por narrativas dos feitos daquelas moradoras, quando da chegada ao bairro ou para a manutenção da vida posteriormente.

Em cada encontro na Restinga, nossas interlocutoras interpunham aos diálogos o desejo de comentar a vida no bairro. De início, confidenciavam-nos suas preocupações com os conflitos do tráfico de drogas e com a violência do entorno; lamentavam também a precariedade dos serviços de saúde, como se quisessem visibilizar os fatos àqueles que chegavam. Mas, de outra parte, versavam sobre as conquistas históricas da comunidade e sobre a necessidade de valorizar o que já fora realizado, procurando relativizar as adversidades. 


\section{pro.posıções}

$e$-ISSN 1980-6248

http://dx.doi.org/10.1590/1980-6248-2019-0041

À sequência, convidamo-las a realizar ensaios fotográficos e rodas de conversa concernentes. Entregávamos máquinas fotográficas analógicas descartáveis e, ao levar as imagens reveladas semanas depois, iniciávamos conversações mediante a apresentação das fotos pelas participantes, que, à continuidade, vertiam para interlocuções ampliadas, sem moderação. Assim, procurávamos intercalar interações dirigidas e ocasiões de diálogos abertos e espontâneos. Tal disposição nos ajudou a diversificar as narrativas, extrapolando as falas iniciais sobre as situações cotidianas imediatas ou a repetição de temas. Acreditamos que as expectativas culturais associadas à fotografia analógica, registros supostamente dignos do "belo", do "extraordinário" ou do "importante" (Martins, 2009), apoiaram-nos nuançando os depoimentos, variando os relatos sobre as experiências da localidade.

\section{As nuances na participação}

A dinâmica do trabalho excedeu o que programávamos, sendo configurada na medida da participação de nossas companheiras de diálogo. Assim que chegávamos e nos cumprimentávamos, a sala da residência ficava ruidosa. Parecia um encontro de amigos ou familiares. Na mesa, aguardavam-nos alguns salgadinhos, talheres, pratos e xícaras. Percebíamos a gradativa inclusão de nossa proposta entre suas práticas de sociabilidade e, também, um modo de nos receber: a casa arrumada, os cumprimentos acolhedores, as conversas sobre trivialidades à chegada, a oferta de algo para comer.

Não tardou muito e nossas colegas propuseram que intercalássemos as residências para os encontros. Desta forma, as demais também puderam receber o grupo pelo menos uma vez, apresentaram suas moradias e ofertaram a possibilidade da partilha à mesa. Então, já tinha se estabelecido tacitamente uma rotina: cada participante trazia algum prato consigo para compartilhar ao final da roda, no momento destinado ao chá e café. Acompanhando-as, também levávamos comida e bebida para compartilhar, assim como não podíamos sair sem antes partilharmos à mesa alimentos, notícias e causos.

Assim, muito rapidamente, nossas atividades foram incorporadas às suas agendas e elas atuaram ativamente na conformação dos encontros, com as temáticas e na configuração do modo de interagir. Não raro, havia familiares acompanhando nossas atividades; vez ou outra, convidavam por conta própria outras moradoras do bairro para integrarem o projeto, dizendo 
que seria importante para elas ou que teriam muito a contar também. Ademais, o trato lúdico e jocoso passou a percorrer todos os momentos do encontro.

E é desde tais tomadas de posição, sobretudo, que entendemos oportuno analisarmos a dinâmica das conversações e a forma das narrações.

\section{Reflexões sobre a dinâmica e a forma}

No que tange, então, à configuração das conversações, vale observar algumas idiossincrasias. Tão logo se encerrava uma ou outra exposição individual acerca das fotos, usualmente escutada com atenção e/ou acompanhada de falas de apoio ou elogios das colegas, irrompiam conversas diversas e transversais. Concluído o trabalho sobre os ensaios fotográficos, essa era a forma preconizada nos diálogos que se seguiam, incluindo-se aí os instantes dedicados para a partilha à mesa.

Como que em meio às espontaneidades de uma confraternização, a conversação oscilava entre instantes de destaque a uma fala individual e diálogos simultâneos e com temáticas correlacionadas ou derivativas. Do argumento lançado por uma pessoa seguiam-se comentários ou narrações complementares ou divergentes. Em geral, nenhum assunto era mantido tempo suficiente para que um conflito entre posições se exacerbasse; logo surgia quem contemporizasse e encaminhasse o rumo da interlocução para outro tema. A astúcia jocosa, a brincadeira ou falas sobre a impossibilidade de consensos em certos temas arrefeciam os ânimos e mantinham a fruição sociável. O mesmo percebíamos quanto ao protagonismo individual: caso alguém se excedesse em suas narrativas, os demais procuravam interpor considerações ou dispersavam em diálogos lateralizados, evitando o monopólio da fala. Vejamos um trecho de nossas transcrições:

Maria Clara: Isso da escola de samba foi aí um grupo de loucos que um dia teve uma ideia [referindo-os como precursores] Aí, depois de dois anos, a gente já tinha um dinheirinho pra fazê uma sede pra nossa escola de samba. Aí, era lá perto d'aonde hoje é o Cecores [Centro de Comunidade da Vila Restinga]. Quando começaro a construir a segunda unidade de casas, nos correro de lá. Aí, nós viemo aqui pra esquina, perto da delegacia que tinha ali.

Ênio: Era uma casa verde de madeira.

Loiva: Lembro dessa aí. Eu já tava aqui...

Maria Clara: Aí, pedimo pro delegado nos deixá ensaiá umas duas vez por semana. Era o Chicão o delegado. Era Chicão, né?

Loiva: É, pode sê. Irmão da Clara Maria. 
Maria Clara: Ele permitiu. Deu um sermão... "sem bagunça e coisa e tal". [risos das presentes] Eva: Esse nunca usô carro pra entrá aqui. Entrava a pé: um revólver aqui e um cassetete aqui [batendo aos lados do corpo com as mãos]. Batia sem pena!

[Em interlocução lateral]

Loiva: Não tinha medo de arma.

Nila: Encarava mesmo?

Loiva: Tu apontava a arma e ele vinha com cassetete pra cima.

Maria Clara: Mas sei que ele dizia que era pra ensaiá até meia noite e nós ia até quatro, cinco hora da manhã. [risos novamente]

Loiva: E tinha um fuquinha na frente da delegacia. Era pra tudo: atendia ocorrência policial e de saúde... Era ambulância também... [risos] (Casa de Loiva, set./2014)

Embora a contação dos feitos desse a tônica para muitas das falas, esses tomavam a forma de pequenos causos e anedotas nas conversações, ora de acontecimentos partilhados com as colegas, ora de ocorrências vividas individualmente, mas similares e concernentes ao contado por outrem. Porém, não havia necessariamente linearidade entre os depoimentos; o fluxo tomava redirecionamentos, às vezes bifurcações, conforme intervinham as participantes, dispondo assuntos que lhes interessava compartilhar.

Se observamos as pequenas narrativas produzidas nas rodas, percebemos que não eram meros relatos. Certa "arte" se consubstanciava na contação, com variados níveis de domínio entre nossas interlocutoras. As falas podiam incluir o destaque de uma ocorrência desconcertante ou engraçada, uma proeza, uma passagem de superação de adversidades ou um caso de distinção pessoal. Para tanto, a performance do narrador incluía a proposição de uma situação e um dilema, sendo que daí se indicava protagonismo das personagens em seu trato, e podia se insinuar ainda certo suspense, que, então, se convertia num desfecho em tom cômico ou, por vezes, de ênfase trágica ou épica. Depois de concluída a contação, o causo mantinha-se como ambiência interativa, em derivação nos comentários empáticos das colegas de grupo, ou nos detalhes agregados que o narrador propunha ante as reações das interlocutoras.

Cabe frisar que, se os causos contados assumiam uma configuração um tanto aproximada das obras narrativas analisadas pela literatura, indicando "funções", "ações" e "narração" (Barthes, 2011), aqueles se constituíam em direção ao privilégio da denotação, de modo que a conotação se apresentava sutilmente. As falas eram dispostas como depoimentos do experienciado; o que se deseja indiciar poderia ser depreendido não tanto por signos deliberados como índices ao longo do narrado, mas pelo conjunto da obra e o que o feito poderia representar. De maneira geral, os comentários jocosos ou de apoio na roda indicavam 
rumos de interpretação para a situação contada. A seguir, dispomos a transcrição de um dos causos narrados:

Aí por 75, eu comecei a vir e ficar por aqui, né. Aí... fevereiro, março. Aonde eu achei nesse canto aqui, uma casa, que era um, bah, bem certinha pra mim! O preço, a casa, a família... Mas eu, eu sofri tanto, tanto, pra adquirir esse local e essa casa - essa casa, não, essa casa não era, era uma taperinha de madeira [sinalizando ênfase].

$\mathrm{E}$ aí, o senhor dono da casa botou uma plaquinha ali na frente, que queria vender a casa. E a minha comadre Teresinha disse: "ah, tá, ali tem uma casinha pra vender". Aí, eu vim aqui, vi a plaquinha, entrava aqui, conversava com os dono da casa - tudo certo, vamo vendê pra senhora, aquela coisa... mas e o dinheiro?

Aí, o meu cunhado me chamou um dia e disse que ia vendê a casa que a gente morava. A gente tava de empréstimo na casa dele, ali na São Francisco. Bah, e agora... Ffisionomia indicava embaraço; instaura-se um breve silêncio]

De manhã, um dia de manhã, apareceu um anjo de guarda lá na São Francisco. Eu estava num dia de folga, estava sentada na frente, desarvorada, não sabia pra que lado, que rumo que eu ia tomá. Chegou uma mulher e perguntou assim pra mim:

- A senhora não sabe uma casa pra vendê por aqui?

- Olha, minha senhora, eu tenho a impressão que essa casa que eu estou morando brevemente vai ser vendida.

- Ah, por que, moça, a senhora tá morando e é proprietária?.

— Não... - Aí, eu contei a história e tá. Ela disse:

- E o que ele está pedindo?

— Eu acho que não é muita coisa. É na média de 120 cruzeiro.

- Ah, é? E como é que eu posso falá com esse senhor?

- Olha, a senhora faz assim: vem aqui de noite que eu trago ele aqui, né. Lá pela tal hora da noite, eu trago ele aqui, a senhora conversa com ele aqui. E se vocês se acertarem, melhor.

Aí, ela virou as costa e eu peguei o ônibus e fui lá na Érico [av. Érico Veríssimo] falar com ele. Eu digo:

— Olha, Lele, o negócio é o seguinte, eu acho que arrumei um comprador praquela casa lá no São Francisco.

—É??

— É. Uma mulher assim, assim, assim [gesticulando sequencialmente com a mão direita]. E hoje de noite ela vai lá pro caso que tu pudesse ir lá, acaso acertar com ela lá, viu. Eu ofereci pra ela 120 mil. — Ele quase caiu da cadeira.

- Não, mas é muita coisa.

— Não. Negócio é negócio. [risos das presentes] 120 cruzeiro. 100 é teu e 20 é meu. Que que tu acha?

—É, se ela tiver, né?!

— Então, tá fechado o negócio. [batendo a mão na mesa. Risos novamente]

\section{É, a vida não era que nem hoje. A gente se virava! [comenta uma das colegas de grupo]}

Aí a mulher foi lá de noite, sete horas da noite, oito horas, sei lá. Aí, olhou toda a casa. Ela gostou da casa e a casa bem arrumadinha, limpinha, que eu sempre fui caprichosa, né? Olhou os fundos, tinha uma outra casinha nos fundos, né? Só que ela não sabia que nós tava sem água e sem luz [mudando o tom de vo:], porque a vizinha do lado, a Dona... uma senhora de religião, 
me esqueci agora o nome dela, cedeu um "gato" - fez um "gatinho" pra nós, né? Aí, tá. E tinha luz na casa, então ela não se assustou.

Sei que se arrumaram lá. E disse no final:

— Não, agora tudo que tivé que tratá, a senhora trate com o Seu Adão (o Lele).

Aí, eu fiquei com um problema de consciência. Depois que ela foi embora, o Lele ia saindo e eu disse:

— Vem cá, Lele. O negócio é o seguinte: tu sabe que nós tamo com a luz cortada, né?

— Sei. Tá, essa despesa aí, esse gasto aí é com vocês, vocês que vão pagá. Tu e o Ênio [esposo], já que tu me pediu, né, esse dinheiro aí, agora vocês têm um dinheirinho na mão. Isso aí, eu não me meto. Aí, quando eu recebê o dinheiro, eu já chamo vocês, dou o dinheiro pra vocês.

Tá, aí passou uns dias, tudo, ele fez, recebeu o dinheiro. Aí nós recebemos o dinheiro, eu e o Ênio. Aí foi lá, a primeira coisa, pagamo a CEEE [Companhia Estadual de Energia Elétrica]. Paguei, acertei a luz. Fui no DMAE [Departamento Municipal de Água e Esgotos], pá, acertei, tudo certo. Aí, a CEEE religou a luz, veio o DMAE, religou a água. Aí, essa senhora voltou lá em casa. Mas aí, nessas alturas, como ela demorô um pouco, né? Parece que ela era do interior. A nossa vida ali dentro da casa já tava tudo resolvido, beleza!

Aí, eu tinha também um dinheirinho guardado escondido do Seu Ênio. [risos das presentes] Foi aonde eu juntei e fiz o negócio com essa casa aqui. (Maria Clara, maio/2015)

Noutra ocasião, uma de nossas interlocutoras, contava empolgada o nascimento do neto. Procedeu mencionando quando nascera o bebê e o nome que lhe fora dado, em cuja escolha, aliás, teria participado. Então, passou a lembrar de situação vivida por ela própria: teria havido uma novela em que a atriz Rosa Maria Murtinho interpretava personagem cujo nome lhe agradava, que também era o de uma amiga. Esta, por sua vez, insistia que se colocasse seu nome na filha de nossa colega de grupo, o que acabou ocorrendo. Na sequência, outras mulheres do grupo comentaram as circunstâncias de atribuição de nomes aos seus parentes.

O acontecimento narrado acima, talvez bastante comum, interessa-nos como mais um exemplo do que argumentamos e pode nos sinalizar para o característico das narrações em foco. A memória foi disparada pelo acontecimento (nascimento do neto), trazendo em narrativa um pequeno itinerário de atos, agentes e relações, em associação aos quais se compartilhavam ainda alguns juízos (beleza dos nomes, relevância da atriz etc.). A escolha de um nome para um parente fora disposta, assim, numa rede de pertenças, sentidos e distinções. Neste caso, como para o conjunto dos enredos que observamos, tratava-se de: expressar as reciprocidades com entes próximos ou elos com personagens reconhecidas; evocar as astúcias postas em ação; assinalar que não é mero ato, mas, sim, o fruto de uma elaboração significativa e uma agência. 


\section{pro.posıções}

$e$-ISSN 1980-6248

http://dx.doi.org/10.1590/1980-6248-2019-0041

É importante assinalar, aliás, que a performance se dispunha para o momento da interlocução, e os elementos a serem realçados podiam variar conforme os interlocutores. Percebíamos, por exemplo, que a chegada de novos integrantes de nossa equipe motivava modalidades específicas de fala: junto da necessidade de se apresentarem pessoalmente vinha a exposição de aspectos do bairro ou das experiências (entre adversidades e superações), atualizando informações pronunciadas no início de nossa interação. Com o convívio regulando certo conhecimento mútuo, com códigos e acordos já sedimentados orientando os diálogos para outros temas, tal retomada de alguns enunciados nos sinalizam para certas "imagens" de primeiro contato, aquelas que se desejava enunciar ao recém-chegado ou ao de presença episódica, algo a considerar e contrastar com as partilhas de longo prazo.

Algumas vezes, quando versavam sobre memórias de feitos compartilhados, estes pareciam ser verbalizados a partir da fruição conjunta da lembrança entre as pessoas, como se ela fosse possível porque ambas as protagonistas do ocorrido estavam ali, juntas. A fala era feita convocando por vezes a anuência ou comentário de uma colega ou outra de itinerário. A evocação mnemônica era distinta sem a presença da "amiga que também esteve lá".

Em que pese, todavia, nossos esforços de sistematizar o modus vivendi que caracterizou nossas interações nas rodas de conversa, convém assinalar que não temos a pretensão de enunciar toda a relevância deste "estar-junto". Cremos apenas que nos acercamos do cotidiano de nossas interlocutoras à medida que configurávamos nossos encontros em articulação com seus modos de conversação e partilha. Há muito que se conhecer dos detalhes desta prática, seja pela ruptura dos tempos demasiadamente programados, instaurando certa "expansão" do presente desde a duração afetiva da fruição, seja pela intensidade da socialização de informações e saberes, dada a diversidade, a transversalidade e a dinamicidade com que as pessoas engendravam suas participações (mesmo que reconheçamos ali posições e regras de enunciação).

Cabe, não obstante, trazer algumas inferências acerca do percurso construído em campo, assinalando algumas das resultantes de nossas escolhas metodológicas. 


\section{pro.posıções}

$e$-ISSN 1980-6248

http://dx.doi.org/10.1590/1980-6248-2019-0041

\section{Repercussões do percurso: o sociável e as artes de dizer}

Trazendo algumas inferências acerca do percurso construído em campo com as rodas de conversa, entendemos possível assinalar algumas das resultantes de nossas escolhas metodológicas. Primeiramente, temos em conta que ir à casa de nossas interlocutoras e partilharmos momentos em seus territórios potencializou nossa aproximação ao cotidiano. Por certo, havia os interditos; nem tudo era falado a nossa frente. Seria ilusório crer que nos colocávamos numa relação plenamente horizontalizada; éramos, em boa medida, "gente de fora" ${ }^{" 6}$. Contudo, cremos que a dinâmica coproduzida ensejou confiança à veiculação das narrativas; adensou as discussões ao dispor reflexividades desde um ambiente relativamente habitual para aquelas senhoras.

Vejamos alguns aspectos. Depreendemos que os ambientes nos quais as rodas aconteceram nos traziam informações a ponderar e que, não raro, se tornavam motes para as conversações. Assim foi com as fotos de familiares, os símbolos dos êxitos educacionais ou os artefatos artesanais que adornavam as residências. Por eles, fomos informados de prioridades, referências simbólicas e saberes compartilhados: aquelas senhoras expressavam sua valoração positiva da escolarização, embora a tivessem experienciado de maneira truncada na maioria dos casos; insistiam na necessidade de manutenção dos laços de apoio mútuo com familiares; compartilhavam técnicas na produção de artesanato doméstico.

Compreendidas em articulação a outras técnicas que apropriamos em campo, os ensaios fotográficos e as conversações traziam elementos a considerar para entrevistas narrativas, ora complementando-as, ora trazendo aspectos a contrastar. Não raro, os ensaios livres acabavam sendo temáticos, enfatizando pertenças e o que fora extensivamente envolvente no percurso de vida: a relação com o território; a família, os filhos e/ou o casamento; as atribuições profissionais; os modos de fruição da sociabilidade local. Por outro lado, explicitavam-se as contingências do que fora partilhado a cada procedimento: consideremos, dentre outras

\footnotetext{
${ }^{6}$ Vale citar que, ao longo do processo, fomos incluídos em suas provocações lúdicas, fazendo com que nos sentíssemos mais próximos de nossas interlocutoras. Certa feita, disseram em tom jocoso: "esses aí são uns maloqueiros; não saem daqui". A sentença sinalizava que nos era então destinado um lugar diferente, não somente de acadêmicos e de pessoas "vindas de fora". Logicamente, não estamos afirmando uma situação de equivalência. Como intérpretes daqueles que chegavam, situavam-nos como visitantes (não residentes na comunidade) e, mesmo depois de bastante tempo de interação, mantinham-se os interditos. Falamos de aproximação gradual, mas que não disfarça posições sociais distintas e precisa ser lembrada como configuração das contingências das interpretações que produzimos.
} 


\section{pro.posıções}

e-ISSN 1980-6248

http://dx.doi.org/10.1590/1980-6248-2019-0041

possibilidades, as ênfases dadas nas entrevistas aos êxitos e fracassos dispostos em um itinerário desenhado pelas superações rumo a certa unidade biográfica; e, nas rodas com colegas, o destaque às artimanhas e astúcias compartilhadas ante a precariedade e a desigualdade, em experiências permeadas por descontinuidades.

Pelas rodas de conversa, soubemos também de outros feitos: as fruições de lazer possíveis àquelas mulheres em suas juventudes, geralmente deixadas de lado nas entrevistas em favor do que fora protagonizado destacadamente no trabalho e na subsistência; discretas referências religiosas e seu lugar na interpretação de acontecimentos do cotidiano; as táticas diante da insegurança no bairro; a importância dos laços de reciprocidade locais, com familiares e amigos especialmente, como suportes à existência.

Poderíamos dar alguns exemplos nesse sentido. Certa vez, Joici contou que aguardava um pintor para concluir as reformas na residência. Teria estado lá um profissional conhecido, que poderia fazer o serviço, mas que não aceitara por ser demasiado trabalho, que não lograria concluir naquele momento. Então, ela explicou que precisaria esperar que ele tivesse tempo. Segundo disse, seriam poucos em quem se confiar na comunidade, dado que "quem entra em casa, fica sabendo como e onde se fecha e chaveia as portas".

Noutro momento, discutiam a morte do ator Domingos Montagner, que ocorrera por afogamento no rio São Francisco no período em que se produzia uma novela naquela região. O acidente consumado após o ator decidir mergulhar no rio foi debatido ponderando articulações do transcendente com a realidade circunstanciada, terrena. A interpretação considerava que os "espíritos" ou as "forças de outro plano" teriam sido provocadas na condução das gravações das cenas da novela. A personagem de Montagner teria levado tiros quando andava a cavalo e, então, chegando à margem do rio, caiu na água e acabou boiando na correnteza até ser encontrado por índios que, por pajelança, trouxeram seu espírito de volta. Contaram-nos que os pajés teriam ido ao programa "Encontro", da mesma emissora de TV, e narrado como procederam no ritual. Assim, não eram atores, mas sim sacerdotes de uma tribo real. As falas de nossas interlocutoras somaram a isso considerações sobre certo magnetismo do rio São Francisco, que atrairia os corpos, e o pronunciamento posterior de uma vidente que havia previsto a morte do ator para aquele ano. Interessante observar a bricolagem e a cosmologia em jogo. Presenciamos uma partilha interpretativa-especulativa que, acionando diferentes argumentos esotéricos, dispunha em respeito ao transcendente e, em articulação, contava com 
ele para intervenções terrenas, de forma que, como assinala Martins (2011), associava fatos cotidianos e o imaginário na explicação do mundo.

Eis que, por tal caminho, também provocamos reflexividades sobre a história do bairro, quando aquelas vinculadas à militância comunitária comentavam com as demais os marcos cronotópicos da produção de sua comunidade: a fundação da escola de samba; a condição original e as precariedades vencidas; as modificações conquistadas para as ruas onde hoje transitavam. E assim foi com as passagens de racismo: houve quem alegou nunca ter sofrido racismo e, perplexa ao escutar as colegas, enunciou seu passado de maneira diferente.

As pessoas ficavam falando em racismo lá no meu grupo do coral. Eu dizia: "eu não passei racismo. Tive uma vida muito boa!”. Mas aí, fico escutando vocês falá aqui. Eva disse isso do patrão que deixava dinheiro em casa pra vê se ela pegava. Já não sei...

Quando era criança, meu pai veio de Santa Cruz ali pra Viamão [região metropolitana de Porto Alegre]. Ele tinha uns conhecido e fui trabalhá numa casa de freira ali na Cidade Baixa [bairro próximo ao centro histórico de Porto Alegre]. Ele dizia: "pobre tem que procurá uma árvore que tenha bastante galho e que dê bastante sombra". Nossa! Gostavam muito de mim lá. Pois é... [breve silêncio] mas tinha uma Irmã que dizia que eu era uma "negrinha de alma branca". Eu achava que era elogio! [risos] (Nila, mar./2016)

Em articulação com as informações que possamos depreender das narrativas desde a triangulação de diferentes técnicas apropriadas (algo já bastante frisado pela literatura sobre metodologias de pesquisa qualitativa), entendemos que o mais significativo a ser enfatizado neste artigo concerne às repercussões heurísticas da forma como as rodas de conversa se produziram; de outro modo, atermo-nos também à maneira como atuaram os sujeitos e não somente ao que narraram.

Lembrando Simmel (2006), poderíamos admitir uma dinâmica comum à "conversa sociável", tomando-a idealmente em sua configuração: a centralidade da sociação em relação aos assuntos conversados; a disposição de relações horizontalizadas, com a interposição de limites à proeminência individual dos interlocutores; a propensão a promover mutuamente o máximo dos valores sociáveis (alegria, vivacidade etc.). O modo como coproduzimos as rodas de conversa, ao cabo, sendo boa parte do tempo transcorrida sem diretividade nossa nos temas e rotinas (e no espaço habitual de nossas interlocutoras), precisa levar em conta tal caracterização. 


\section{pro.posıções}

$e$-ISSN 1980-6248

http://dx.doi.org/10.1590/1980-6248-2019-0041

Entendemos que a configuração dos encontros evocava o socialmente naturalizado, a dinâmica sociável da conversa. É preciso reconhecê-lo não só para ter aí novas bases de informação desde tal técnica, mas para ter em conta os limites dados pelo que se evoca quando apropriamos modos de interagir social e culturalmente defluentes. Numa interação sociável, pela dinâmica de manutenção da sociação, pode se dispor o interdito, o assunto que não pode avançar por exemplo; o depoimento de um que tende a não receber contradição veemente do outro ${ }^{7}$.

Não obstante o limite mencionado, pensamos possível avançar nas reflexões se voltarmos à maneira como atuavam nossas interlocutoras, como dissemos acima. A participação daquelas mulheres na configuração dos encontros convida-nos a pensar as nuances específicas da configuração de uma dinâmica comumente experienciada em conversações sociáveis, aproximando-nos de seus cotidianos. Dentre os aspectos que gostaríamos de realçar aqui, começamos pelos laços de reciprocidade. Nossas colegas nas rodas trouxeram não só uma prática de partilha à mesa; acompanhava aquela ritualidade o pressuposto da manifestação do interesse comum e do contradom. O rodízio das residências e a composição da mesa desde a contribuição coletiva tacitamente esperada pareceu-nos a expressão mais evidente do que afirmamos.

De outra maneira, os recorrentes convites a outras moradoras para participarem de nossos encontros remetemos também à produção do ato recíproco, mas então associado à forma de atuação de parte daquelas mulheres em sua comunidade. A dimensão de gênero perpassava a produção de certo capital social, orientando sobremaneira à atuação local (como sugere Sacchet, 2009), neste caso, dirigido à proteção mútua entre mulheres via inclusão em práticas educativas, de lazer e sociabilidade, como era costumeiro relatarem e a partir das quais apropriaram nossas rodas de conversa.

Ainda em menção ao componente de gênero, não há como não assinalar os contrastes entre os inúmeros depoimentos de protagonismo, em destaque à atuação feminina e crítica à passividade masculina. Ou, por outro lado, a disposição a predominarem na organização de

\footnotetext{
7 Para dar um exemplo bastante trivial, algumas vezes após nossas rodas de conversa, em diálogos individuais, algumas das participantes vinham confidenciar que o narrado por uma colega não correspondia à realidade, mas que não poderia mencionar em grupo, porque seria constrangedor. Cremos possível tomar este aspecto (um tanto corriqueiro) para nos perguntarmos pelos costumes do sociável.
} 


\section{pro.posições}

$e$-ISSN 1980-6248

http://dx.doi.org/10.1590/1980-6248-2019-0041

louças e alimentos à mesa e gerir a produção do momento de partilha, indo e vindo da cozinha à sala e, em geral, tentando dispensar os homens presentes de participar naquelas tarefas.

Convém retornar a Simmel (2006) e considerar que "a sociabilidade é também a forma lúdica das forças éticas da sociedade concreta" (p. 77). Ali estavam expressões da reciprocidade, do modo de atuação na comunidade e no espaço doméstico e das performances individuais nas disputas cotidianas. A conversação, especificamente, configurava-se nas tensões entre participações individuais e sua adequação ao contexto; mais concretamente, a dinâmica da conversa se produzia nas figurações do singular, distintivo, mas dispondo-o em partilha e em modos de manutenção dos laços.

Neste sentido, recuperemos as performances narrativas individuais analisadas no tópico anterior com a ajuda de Certeau (2011). Provoca-nos o autor a pensar sobre as homologias entre as "astúcias da prática" e as "astúcias da narrativa". Diz ele que o conto popular é a teoria da prática contada, "é um saber-dizer ajustado ao seu objeto" (p. 141), que não relata, narra. As "artes do fazer" e do "dizer" se associam no modo astucioso de sua produção: de um lado, o suspender temporário dos obstáculos de uma relação assimétrica para sair adiante; de outro, a configuração da proeza desde o "tato" para produzir não o ato, mas os efeitos expectantes aos interlocutores. A narrativa não descreve, agencia os fatos e, assim, indicia também o sistema de interpretação que a constitui: "sombras da prática cotidiana que consiste em aproveitar a ocasião e fazer da memória o meio de transformar os lugares" (p. 150).

As performances de nossas interlocutoras tentavam indiciar o teor do vivenciado. Então, aventamos a hipótese de que os causos dispostos à conversação, também na forma, eram a "teoria" de um sujeito: mulheres idosas que, diante das condições adversas de itinerários em contextos de periferia, tentavam agenciar elementos para seu reconhecimento, narrando as táticas de quem não tinha um "próprio" (Certeau, 2011) e operando uma estética relacional de manutenção dos laços de reciprocidade que as constituíam e amparavam, onde os aparatos institucionais costumam ser insuficientes e/ou de acesso desigual.

Um último exemplo pode ser bastante elucidativo, trazendo a apropriação em narrativa de uma das experiências construídas no próprio processo que ora relatamos. Após a conclusão de nossas incursões, e por ocasião de um convite para que nossas colegas nas rodas fossem à universidade partilharem experiências com os graduandos, uma delas narrou entusiasmada: 
Olha, eu tenho problema de visão. Tô tratando e, se Deus quisé, vô melhorá!

Mas tô lá no meu canto e chega esse bando de maluco aqui. [referindo-se aos pesquisadores; risos dos presentes] É, digo maluco, porque só sendo maluco pra dá uma máquina fotográfica na mão de uma pessoa que não enxerga. [risos]

Mas aí que tá! Eu contei com ajuda de minha amiga, Nila, e ela foi minhas mão. [tocando a mão da colega] Foi a Nila e mais alguém... Acho que foi a Eva. Bom, sei que ela ia comigo e eu ia dizendo: "tu tá vendo isso, isso e aquilo. Então, tá...".

Olha, eu tava num momento difícil, e essa gente veio e me mostrô que dava pra fazê. E eu fiz, tá aí! (Luci, ago./2016)

Eis aí, enfim, nosso exercício narrativo, atinente às evocações e sintonias experienciadas em campo. Também o caminho de uma partilha e da elaboração de tempos em comum, provocadas pela dinâmica em que fomos inseridos, na forma como nos arrebatou em acolhida para fruição e regozijo em sutis reflexividades. Talvez, enfim, seja consoante recordarmos aqui a citação de Karen Blixen (Isak Dinesen) feita por Paul Ricoeur (2015) em conferência:

Os pesares, sejam eles quais forem, tornam-se suportáveis se os narrarmos ou fizermos deles uma história.

\section{Considerações finais}

Ao longo de nossa narrativa, procuramos abordar a produção de rodas de conversa como procedimento de construção de dados nas pesquisas qualitativas. Para tanto, fizemos um sucinto apanhado de exemplos de apropriação desta, destacando a finalidade usualmente dual, integrada da prática educativa à produção de informações. Assinalamos também a diversidade dos formatos, entre modos mais ou menos diretivos e/ou articulados a outros artifícios de interlocução coletiva conhecidos nas investigações na área de educação. Sobretudo, problematizamos a defluência cultural que constitui a "conversa" para chegarmos à proposição metodológica resultante de experiência etnográfica.

As incursões que foram tema para nossas reflexões situaram as rodas de conversa entre outras técnicas em pesquisa atenta ao cotidiano e as redes de pertença em contextos de periferia urbana. Consideramos tal apropriação com vistas a lançar provocações, fazendo da narrativa dos pesquisadores em campo um exercício de interpretação das conversações produzidas e das narrações que lhes eram concernentes, na dinâmica e na forma que assumiam, para além e em articulação com os conteúdos proferidos. 


\section{pro.posıções}

$e$-ISSN 1980-6248

http://dx.doi.org/10.1590/1980-6248-2019-0041

No percurso que então apresentamos, buscamos analisar as dinâmicas das conversações desde as idiossincrasias da prática sociável, pelo que se constituem tensões entre horizontalidade relacional e participação individual, assim como se configuram uma forma lúdica das forças éticas da sociedade concreta, conforme sugere Georg Simmel (2006). Deste modo, procuramos interpretar o característico das interlocuções em rodas de conversa coproduzidas em território familiar às participantes. Entre outros aspectos possíveis, ponderamos a interposição de redes de reciprocidade locais em nossos encontros, moduladas ainda pela condição de gênero na atuação comunitária e doméstica.

Também por esse caminho, passamos a um olhar sobre as narrativas individuais e/ou coletivas construídas, com a ajuda de Certeau (2011). Aí, nosso exercício de exposição da forma do narrado, em causos e anedotas, destacou a performance do narrador nas "artes de dizer", assumindo o argumento da homologia entre as astúcias da prática e as da narração. Neste sentido, o narrado converte-se em teoria do ato, que, nos contextos em foco, interpretamos como um arranjo tático tributário de uma estética de construção e manutenção dos laços sociais que suportavam o cotidiano.

Entretanto, seria demasiado imaginar que isso exaure a experiência cotidiana de nossas interlocutoras ou mesmo as rodas que estivemos a integrar. $\mathrm{O}$ artigo se presta apenas a reflexões sobre um modo possível de apropriação da técnica, com vistas a contribuir para o fazer entre a pesquisa e a educação. Acreditamos que a atenção à forma das narrações e à dinâmica da conversação pode contribuir com a horizontalidade e a dialogicidade nas rodas de conversa.

\section{Referências}

Barthes, R. (2011). Introdução à análise estrutural da narrativa. In R. Barthes, A. J. Greimas, C. Bremond, U. Eco, J. Gritti, V. Morin, ... G. Genette, Análise estrutural da narrativa (pp. 19-62). Rio de Janeiro, RJ: Vozes.

Bedin, E., \& Pino, J. C. (2018). Interações e intercessões em rodas de conversa: espaços de formação inicial docente. RBEP, 99(251), 222-238. doi:10.24109/21766681.rbep.99i251.3383

Bosi, E. (1994). Memória e sociedade: Lembranças de velhos. São Paulo, SP: Cia das Letras. 
Buaes, C. S. (2015). Educação financeira com idosos em um contexto popular. Educação e Realidade, 40(1), 105-127. doi:10.1590/2175-623646496

Certeau, M. (2011). O tempo das histórias. In A invenção do cotidiano: 1. Artes de faz̧er (pp. 140156). Petrópolis, RJ: Vozes.

ObservaPOA. (2018). Cidade de Porto Alegre. Recuperado de http://portoalegreemanalise.procempa.com.br

Fonseca, C. (2004). Família, fofoca e honra: Etnografia de relações de gênero e violência em grupos populares. Porto Alegre, RS: Editora UFRGS.

Gondim, S. M. G. (2003). Grupos focais como técnica de investigação qualitativa: desafios metodológicos. Paidéia, 12(24), 149-161. doi:10.1590/S0103-863X2002000300004

Jovchelovitch, S., \& Bauer, M. W. (2002). Entrevista narrativa. In M. Bauer \& G. Gaskell (Orgs.), Pesquisa qualitativa com texto, imagem e som: Um manual prático (pp. 90-113). Petrópolis, RJ: Vozes.

Marras, S. (2007). Tarde reconquistado. Novos estudos CEBRAP, (78), 221-231. doi:10.1590/S0101-33002007000200018

Martins, J. S. (2009). Sociologia da fotografia e da imagem. São Paulo, SP: Contexto.

Martins, J. S. (2011). A sociabilidade do homem simples: Cotidiano e história na modernidade anômala. São Paulo, SP: Contexto.

Meinerz, C. B. (2011). Grupos de discussão: Uma opção metodológica na pesquisa em educação. Educação e Realidade, 36(2), 485-504.

Melo, M. C. H., \& Cruz, G. C. (2014). Roda de conversa: Uma proposta metodológica para a construção de um espaço de diálogo no Ensino Médio. Imagens da Educação, 4(2), 31-39. doi:10.4025/imagenseduc.v4i2.22222 
Moura, A. F., \& Lima, M. A. (2014). A reinvenção da roda: Roda de conversa, um instrumento metodológico possível. Revista Temas em Educação, 23(1), 98-106.

Ratts, A. (2003). Gênero, raça e espaço: Trajetórias de mulheres negras. In Anais do $27^{\circ}$ Encontro Anual da Anpocs. Anpocs, Caxambú, MG.

Ricoeur, P. (2015). Memória, história e esquecimento. In Conferência Internacional "Haunting memories? History in Europe after authoritarianism. Budapeste, 2003. Recuperado de http://www.uc.pt/fluc/uidief/textos_ricoeur/memoria_historia

Rocha, A. L. C., \& Eckert, C. (1998). A interioridade da experiência temporal do antropólogo como condição da produção etnográfica. Revista de Antropologia, 41(2), 107-136. doi:10.1590/S0034-77011998000200004

Rocha, A., \& Eckert, C. (2008). Etnografia: Saberes e práticas. In C. Pinto \& C. Guazzelli (Orgs.), Ciências humanas: Pesquisa e método (pp. 9-24). Porto Alegre, RS: Editora UFRGS.

Sacchet, T. (2009). Capital social, gênero e representação política no Brasil. Opinião Pública, 15(2), 306-332. doi:10.1590/S0104-62762009000200002

Sampaio, J., Santos, G. C., Agostini, M., \& Salvador, A. S. (2014). Limites e potencialidades das rodas de conversa no cuidado em saúde: Uma experiência com jovens no sertão pernambucano. Interface, 18(2), 1299-1311. doi:10.1590/1807-57622013.0264

Simmel, G. (2006). Sociabilidade. In Questões fundamentais da sociologia (pp. 59-82). Rio de Janeiro, RJ: Zahar.

Tarde, G. (2005). A opinião e as massas. São Paulo, SP: Martins Fontes.

Warschauer, C. (2004). Rodas e narrativas: Caminhos para a autoria de pensamento, para a inclusão e a formação. In B. Scoz, C. Feldman, M. C. Gasparion, M. I. M. Maluf, M. H. Mendes, Q. Bombonato, ... S. A. M. Pinto (Orgs.), Psicopedagogia: Contribuiçoes para a educaşão pós-moderna (pp. 13-23). Petrópolis, RJ: Vozes. 
Weller, W. (2006). Grupos de discussão na pesquisa com adolescentes e jovens: Aportes teóricometodológicos e análise de uma experiência com o método. Educação e Pesquisa, 32(2), 241-260. doi:10.1590/S1517-97022006000200003

\section{Referências consultadas}

Nunes, M. K. (1990). Restinga: Memórias dos bairros. Porto Alegre, RS: PMPA.

Sommer, M. F. (2011). Territorialidade negra: A berança africana em Porto Alegre. Porto Alegre, RS: PMPA.

Submetido à avaliação em 20 de março de 2019; revisado em 18 de outubro de 2019; aceito para publicação em 26 de novembro de 2019. 